Int. J. Plant Sci. 167(3):483-493. 2006.

(c) 2006 by The University of Chicago. All rights reserved.

$1058-5893 / 2006 / 16703-0009 \$ 15.00$

\title{
REPRODUCTIVE BIOLOGY OF TWO SYMPATRIC SPECIES OF POLYALTHIA (ANNONACEAE) IN SRI LANKA. I. POLLINATION BY CURCULIONID BEETLES
}

\author{
R. M. C. S. Ratnayake,* I. A. U. N. Gunatilleke,† D. S. A. Wijesundara, $\neq$ and R. M. K. Saunders ${ }^{1, *}$ \\ *Department of Ecology and Biodiversity, University of Hong Kong, Pokfulam Road, Hong Kong, China; tDepartment of Botany, \\ University of Peradeniya, Peradeniya, Sri Lanka; and ¥Royal Botanic Gardens, Peradeniya, Sri Lanka
}

\begin{abstract}
The pollination biology of two sympatric species, Polyalthia coffeoides and Polyalthia korinti (Annonaceae), is described in detail. An Endaeus species (Coleoptera: Curculionidae) is shown to be the major pollinator of both species, with Carpophilus plagiatipennis (Coleoptera: Nitidulidae) as the secondary pollinator of $P$. coffeoides. Both Polyalthia species show intrafloral dichogamy (protogyny) with a reproductively inactive phase between the pistillate and staminate phases, although there is no evidence of interfloral dichogamy. A pollination chamber is formed by the inner petals throughout the reproductively active phases. Thermogenesis occurs in P. korinti, with internal floral temperatures up to $6^{\circ} \mathrm{C}$ above ambient levels. The heat is presumably an energy reward for the beetles. Although most pollination systems are regarded as diversified and opportunistic, specialized pollination systems are typical of the Annonaceae. Although P. coffeoides and P. korinti have overlapping distributions, habitats, and flowering seasons and share the same pollinators, the extent of competition for pollinators is likely to be lessened due to the abundance and nonspecificity of the beetles.
\end{abstract}

Keywords: Annonaceae, Coleoptera, pollination, Polyalthia, floral thermogenesis.

\section{Introduction}

The Annonaceae is a pantropical family of insect-pollinated shrubs, trees, and climbers. Most published reports on the pollination biology of the family suggest that the majority of species are beetle-pollinated, with distinct small- and large-beetle pollination systems (e.g., Gottsberger 1999; SilberbauerGottsberger et al. 2003). Although the family is probably ancestrally beetle-pollinated, a diverse array of other insects have been discovered as pollinators, including thrips (Bocageopsis, Duguetia, Oxandra, Popowia, and Xylopia; Gottsberger 1970; Webber and Gottsberger 1995; Küchmeister et al. 1998; Momose et al. 1998a, 1998b; SilberbauerGottsberger et al. 2003), flies (Asimina, Monodora, and Pseuduvaria; Gottsberger 1985; Norman et al. 1992; Su et al. 2005), cockroaches (Uvaria; Nagamitsu and Inoue 1997), and bees (Sapranthus, Unonopsis, and Uvaria; Olesen 1992; Carvalho and Webber 2000; Silberbauer-Gottsberger et al. 2003). There is, therefore, convincing evidence that many pollination systems in the Annonaceae are highly specialized. However, the concept of specialized pollination systems has recently been widely questioned (e.g., Waser et al. 1996), following the accumulation of empirical data that suggest that most pollination systems are diversified and opportunistic.

The pollination biology of paleotropical Annonaceae is poorly known compared to that of the Neotropical Annonaceae. In particular, Polyalthia, which is one of the most species-rich paleotropical genera in the family, is particularly

${ }^{1}$ Author for correspondence; e-mail saunders@hkucc.hku.hk.

Manuscript received August 2005; revised manuscript received January 2006. poorly studied: apart from brief reports of floral visitors, only two detailed studies have been published, on Polyalthia littoralis (Okada 1990) and the Polyalthia bypolenca species complex (Rogstad 1994). A particular problem is that Polyalthia has recently been shown to be polyphyletic (Mols et al. 2004), with most of the constituent clades lacking obvious morphological synapomorphies.

Our research describes the pollination biology of two Polyalthia species, Polyalthia coffeoides and Polyalthia korinti, from Sri Lanka. Both P. coffeoides and P. korinti have similar floral morphologies, with a whorl of three small sepals and two whorls of three petals. The inner petals form a pollination chamber over the reproductive organs immediately before becoming reproductively active. The flowers are hermaphroditic, with numerous densely packed, spirally arranged stamens and carpels. The stamens have a flattened connective extension. Each carpel is densely hairy and bears a sessile stigma. The pollination biology of each species is investigated here by using a diverse range of approaches, including observations of population-level and flower-level phenology, floral thermogenesis, and assessments of floral visitors and effective pollinators; data on fruit set are not given here. We present corresponding data on breeding systems in an accompanying article (Ratnayake et al. 2006).

Preliminary results on the phylogenetic position of $P$. coffeoides (Y. C. F. Su, unpublished data, based on combined $r b c \mathrm{~L}$ and $t r n \mathrm{~L}-\mathrm{F}$ sequences) indicate that it is associated with a clade (labeled "F4" by Mols et al. [2004]), comprising Enicosanthum species and Polyalthia species belonging to sect. Monoon. Corresponding data on P. korinti show that it forms a distinct clade ("F1" in Mols et al. 2004) with three other Polyalthia species (P. cerasoides, P. pendula, and 
P. stublmannii), sister to another clade ("A1-3" in Mols et al. 2004) consisting of Miliusa species. The two species studied here are therefore unlikely to be congeneric, and $P$. coffeoides should perhaps be accommodated in Enicosanthum. The only previous reports on the pollination biology of species in these clades are those published by Momose et al. $(1998 b)$ on Enicosanthum coriaceum and Enicosanthum macranthum, Silberbauer-Gottsberger et al. (2003) on Enicosanthum cf. paradoxum, and Devy and Davidar (2003) on Miliusa wightiana.

\section{Material and Methods}

\section{Study Site}

Field observations of both Polyalthia coffeoides and Polyalthia korinti were conducted in the Menikdena archaeological forest reserve, where the two species are dominant. The Menikdena reserve $\left(7^{\circ} 28^{\prime}-56^{\prime} \mathrm{N}, 80^{\circ} 35^{\prime}-45^{\prime} \mathrm{E}\right)$ is located in an isolated hilly region (113-866 m elevation; Somaweera et al. 2001) in Matale District, Central Province, Sri Lanka (fig. 1). The forest lies in the boundary between the tropical dry-mixed/evergreen forest and semi-evergreen forest zones and therefore represents an ecotone of the two forest types. Mean annual temperatures are $22^{\circ}-28^{\circ} \mathrm{C}$, with total annual rainfalls in the range $1750-2500 \mathrm{~mm}$, largely derived from the northeast monsoon during August to December (Somaweera et al. 2001). The Menikdena forest is legally protected and is relatively well sheltered from human disturbances.

Fifty trees of each species were permanently labeled with metal tags and used in all phenological and experimental studies. Height and diameter at breast height (DBH) were assessed for each tagged tree: the $P$. coffeoides trees ranged between 3 and $16 \mathrm{~m}(x=13 \mathrm{~m})$ in height and 10.5 and $75 \mathrm{~cm}$ DBH $(x=35.4 \mathrm{~cm})$, and the $P$. korinti trees were $1-5 \mathrm{~m}$ $(x=2.5 \mathrm{~m})$ in height and $1.5-18 \mathrm{~cm} \mathrm{DBH}(x=6.0 \mathrm{~cm})$. The size of reproductively mature individuals of $P$. coffeoides necessitated the construction of wooden platforms, which inevitably limited the extent of observations of pollinator activities. Voucher specimens have been deposited in HKU and PDA herbaria, namely, R. M. C. S. Ratnayake 1/03 (P. coffeoides) and R. M. C. S. Ratnayake 2/03 (P. korinti).

\section{Scanning Electron Microscopy}

Specimens were critical-point dried before being attached to aluminium stubs with conducting carbon cement and then sputter-coated with gold. Specimens were then examined using a Cambridge Stereoscan 440 scanning electron microscope.

\section{Floral Phenology}

Population-level phenological studies were conducted weekly over a 3-yr period (January 2002-December 2004) to determine the timing of the beginning and end of flowering, peak flowering times, and whether anthesis is synchronized within and/or between individuals. Flower-level phenological changes were monitored by tagging 10 unopened flowers on each of five individuals of each species. Observations on floral morphology and sexual functioning were made daily before the onset of stigmatic receptivity and subsequently every hour. Changes in the following morphological characters
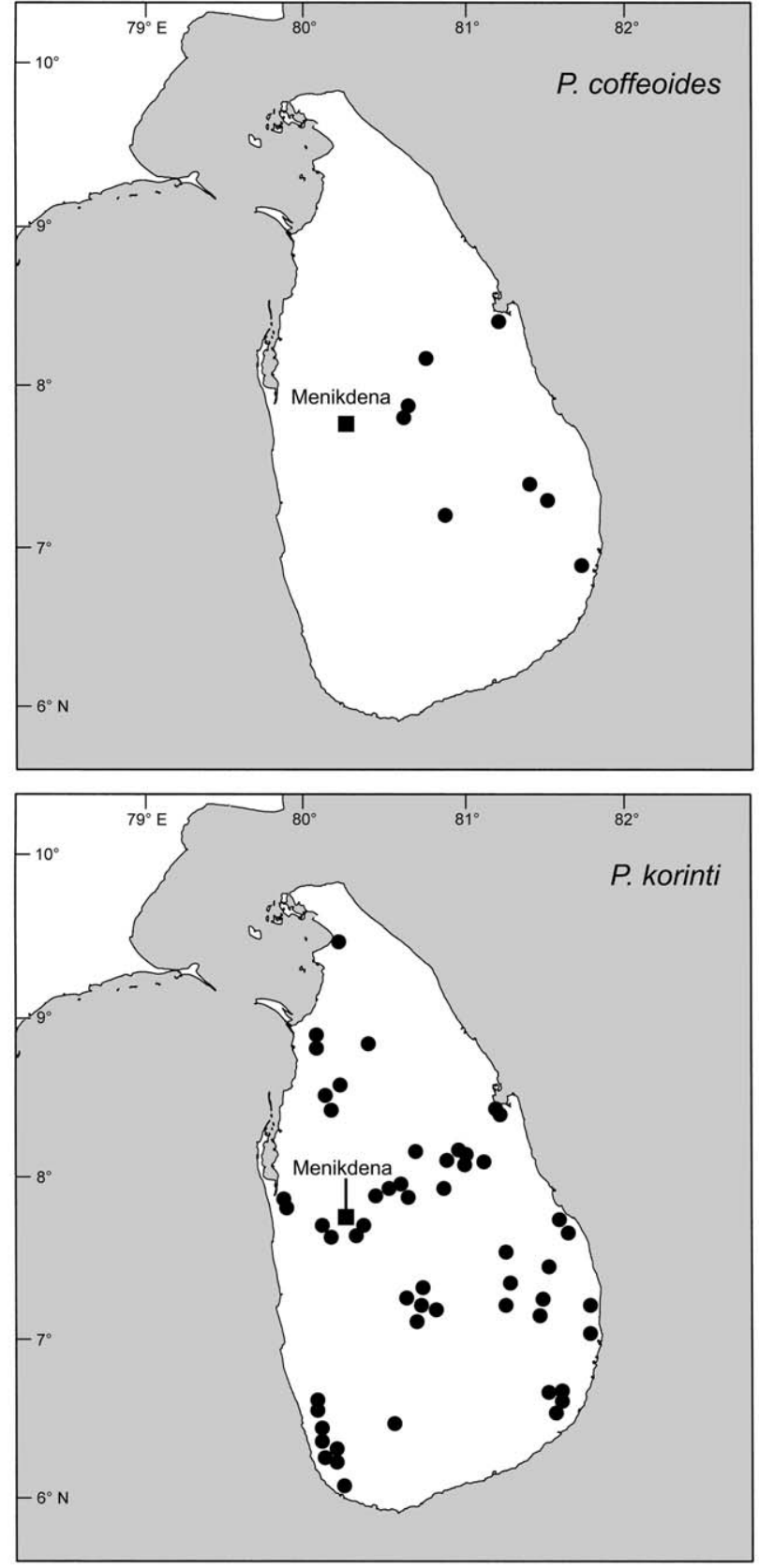

Fig. 1 Location of Menikdena study site (square) and distributions of Polyalthia coffeoides and Polyalthia korinti in Sri Lanka. Distributions based on records published by Huber (1985).

were assessed: orientation of the entire flower (erect vs. pendent); length and width of petals; relative position and shape of petals; color of petals, stamens, and stigmas (using the color standards defined by Kornerup and Wanscher [1978]); and wilting and abscission of floral organs.

The timing of the onset of stigmatic receptivity and its duration were also assessed. Receptivity was initially determined by immersing stigmas in $3 \%$ hydrogen peroxide $\left(\mathrm{H}_{2} \mathrm{O}_{2}\right)$ solution and checking for bubble formation (Dafni 1992); bubbles form as a result of the activity of peroxidase enzymes and are 
indicative of receptivity (Galen and Plowright 1987). Stigmatic receptivity was found to coincide with the appearance of a glistening stigmatic exudate, enabling a simpler visual determination of receptivity. The onset of the staminate phase was apparent due to the mass release of pollen and changes in the color of the staminal connectives.

\section{Floral Thermogenesis}

Temperatures within the floral chambers were recorded using a digital data logger (DataTaker DT 800, DataTaker, Rowville, Victoria, Australia), with type-K thermocouples (welded tip, glass fiber insulated, diameter $0.6 \mathrm{~mm}$, temperature accuracy $\pm 0.0075^{\circ} \mathrm{C}$ ). Measurements were made at 10-min intervals from immediately before the onset of the pistillate phase until petal abscission, using 18 flowers of $P$. korinti and 12 flowers of $P$. coffeoides. Ambient air temperature data were collected simultaneously using a Vaisala 50Y temperature sensor (Vaisala, Helsinki, Finland) at 10-min intervals, attached to the same data logger. The temperature probes were fully cross-calibrated to ensure data consistency.

\section{Floral Visitors and Pollinators}

Extensive observations of the activities of floral visitors were undertaken during daylight hours (0600-1800 hours), supplemented with periodic nighttime observations to ensure that cumulative observations covered the entire anthesis period, from the onset of stigmatic receptivity to the end of the staminate phase. Observations were based on 22 flowers from five individuals of $P$. coffeoides and 32 flowers from eight individuals of $P$. korinti. The number and types of floral visitors were recorded, and samples were collected for subsequent identification. The arrival times and activities of the floral visitors were observed whenever possible.

\section{Results}

\section{Floral Phenology and Morphology}

The flowering periods of the two Polyalthia species overlapped: Polyalthia coffeoides flowered from November to December and January to June (peaking during MarchApril), whereas Polyalthia korinti had two flowering periods, September-April and May-June. The flowering seasons of most individuals were synchronized within the population, although there were a few early- or late-flowering individuals of $P$. korinti.

Flowering levels were consistently low in both species, with generally only two to four reproductively active flowers borne concurrently on an individual tree. There were days within the flowering period when a reproductively active tree did not bear functional flowers. Casual observations suggest that there is no interfloral dichogamy: pistillate-phase flowers often occur alongside staminate-phase flowers within the same tree.

Flower-level phenological changes were similar in both species. The petals opened early in floral development, long before they became functionally active. Flower longevity from the commencement of petal separation to petal abscission was $5.4 \pm 1.9$ and $4.5 \pm 1.2 \mathrm{wk}$ in $P$. coffeoides and $P$. korinti, respectively. For ease of discussion, we have categorized the floral development changes into nine different phases (referred to as stages I-IX; table 1; fig. 2).

The prereceptive open flowers were initially oriented vertically upward (stages I-IV) but gradually became pendent (stages V-IX). This change in orientation was broadly correlated with changes in the relative position of the petals; although both whorls of petals separated early in development (stage II), this was subsequently reversed as the inner petals closed and curved inward, loosely concealing the reproductive organs (stages IV-V). The curvature of the inner petals then reversed, and the adaxially convex central region of each petal came into contact, forming a pollination chamber over the floral organs (stage VI; fig. $3 A, 3 F$ ). This chamber has four openings: three basal apertures located between adjacent inner petals (fig. $3 F$ ) and one apical aperture directly above the stigmas (fig. $3 G$ ). The size of the inner petals determines not only the internal size of the chamber but also the size of the apertures (less than $5 \mathrm{~mm}^{2}$, thereby restricting access to smaller and potentially less destructive floral visitors). The petals of $P$. korinti were consistently green (fig. $3 E-3 H$ ), whereas those of $P$. coffeoides became yellowish from stage $\mathrm{V}$ onward (table 1; fig. 3A-3D).

The flowers were markedly protogynous, with reproductive activity restricted to a 2 -d period. The pistillate phase (stage VII) lasted ca. $12 \mathrm{~h}$ in both species (fig. 4), from ca. 1800 hours on day 1 to 0900 hours on day 2 in P. coffeoides and from ca. 1400 hours on day 1 to $0400-0600$ hours on day 2 in P. korinti. During the pistillate phase, the stigmas were cream colored and noticeably wet due to the secretion of a sticky exudate (fig. 3B). This phase was correlated with the emission of a strong fruity odor.

The pistillate phase was succeeded by an interim period (stage VIII; table 1; fig. 4) before the staminate phase. The interim phase lasted $6-12 \mathrm{~h}$ in $P$. coffeoides and $8-10 \mathrm{~h}$ in P. korinti, during which period the flowers were not sexually functional and floral scents were not produced. The staminate phase, indicated by anther dehiscence, a change in color of the connectives to dark brown, and an increase in floral scent, lasted $12-18 \mathrm{~h}$ in both species, from 1400 hours on day 2 to $0800-0900$ hours the following morning in P. coffeoides and from 1200 hours on day 2 to 0800-0900 hours on day 3 in P. korinti. Freshly dehisced pollen grains were loosely connected to each other due to the presence of a sticky pollenkitt. Short pollen-connecting threads were furthermore evident in P. coffeoides, although not in P. korinti. Anther dehiscence was correlated with abscission of the entire stamen, although the stamens were often observed to remain attached to the floral torus by the extended spiral secondary wall thickenings of the tracheary elements.

\section{Floral Thermogenesis}

There was clear evidence of floral thermogenesis in P. korinti (fig. 5), with elevated temperatures beginning immediately before the onset of stigmatic receptivity. The internal temperature of the flower reached $6.1^{\circ} \mathrm{C}$ above ambient levels during the pistillate phase (peaking around 1600-1900 hours) but fell to only ca. $0.5^{\circ} \mathrm{C}$ above ambient levels during the interim phase. During the staminate phase the following day, temperatures rose to ca. $3.2^{\circ} \mathrm{C}$ above ambient levels by ca. 1600 hours 
Table 1

Flower-Level Phenological Stages in Polyalthia coffeoides and Polyalthia korinti

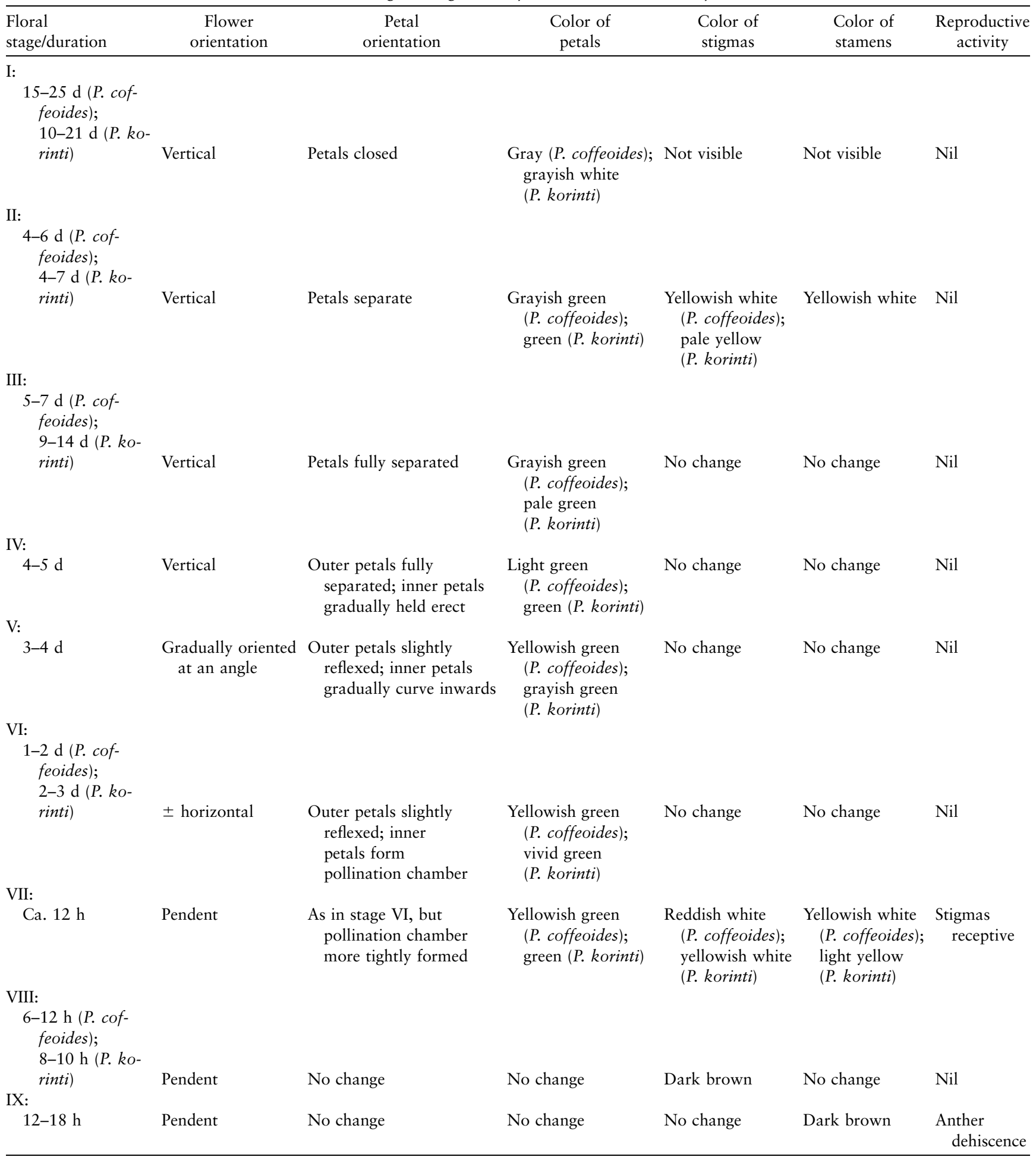

Note. Color nomenclature follows Kornerup and Wanscher (1978).

and then gradually diminished. The coincidence of elevated temperatures with the onset of both stigmatic receptivity and anther dehiscence, and the drop in temperature correlated with the interim phase, suggest that the heat is generated by the flower rather than being merely daytime heat that is retained into the night by the floral chamber.

Evidence for thermogenesis in $P$. coffeoides was rather equivocal, however. The temperature levels recorded inside 


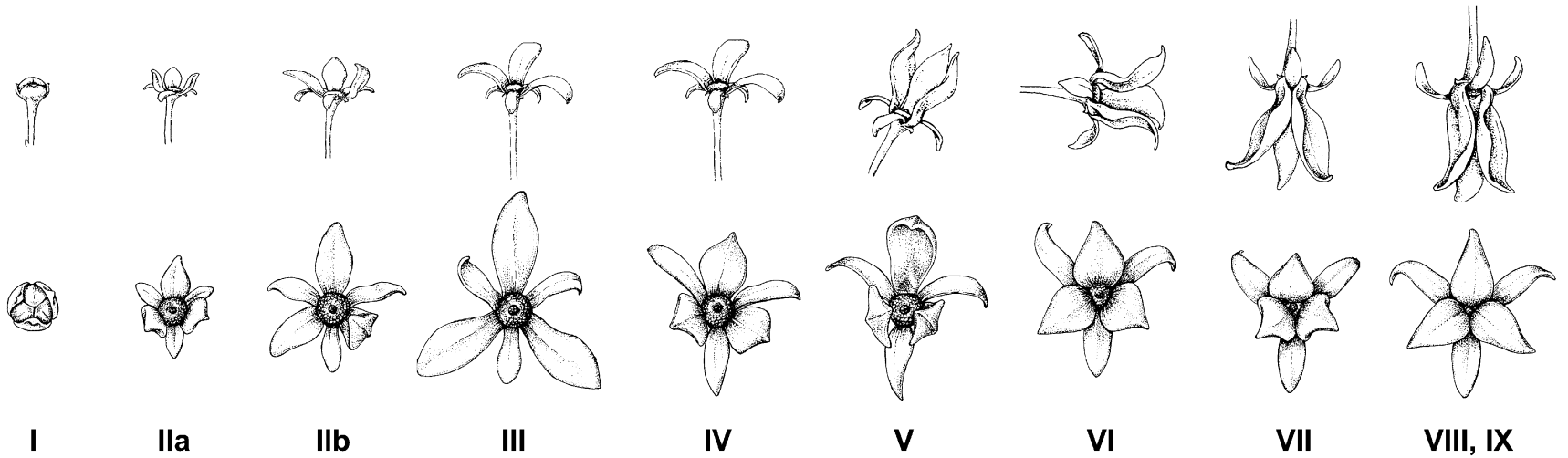

Fig. 2 Flower-level phenological changes in Polyalthia coffeoides during the entire phenological cycle. Top row: lateral view of flowers, showing changes in overall orientation of flower. Bottom row: apical view of flowers, showing changes in orientation and shape of petals. Roman numbers represent the nine different phenological stages described in table 1.

the floral chamber were maximally $0.5^{\circ}, 0.2^{\circ}$, and $0.4^{\circ} \mathrm{C}$ above ambient levels in the pistillate, interim, and staminate phases, respectively. There was no obvious coincidence of elevated temperatures with either stigmatic receptivity or anther dehiscence, nor was there any significant drop in temperature during the interim phase. The slight temperature elevation observed may simply reflect the retention of daytime heat by the floral chamber or the protection of the ther- mocouple probe from air currents that might negatively affect the temperature readings from the external probe.

\section{Floral Visitors and Pollinators}

Of the various insects associated with flowers of $P$. coffeoides, only four species were observed to enter the floral chamber: an undetermined Endaeus species (Coleoptera: Curculionidae), Carpophilus plagiatipennis (Coleoptera:
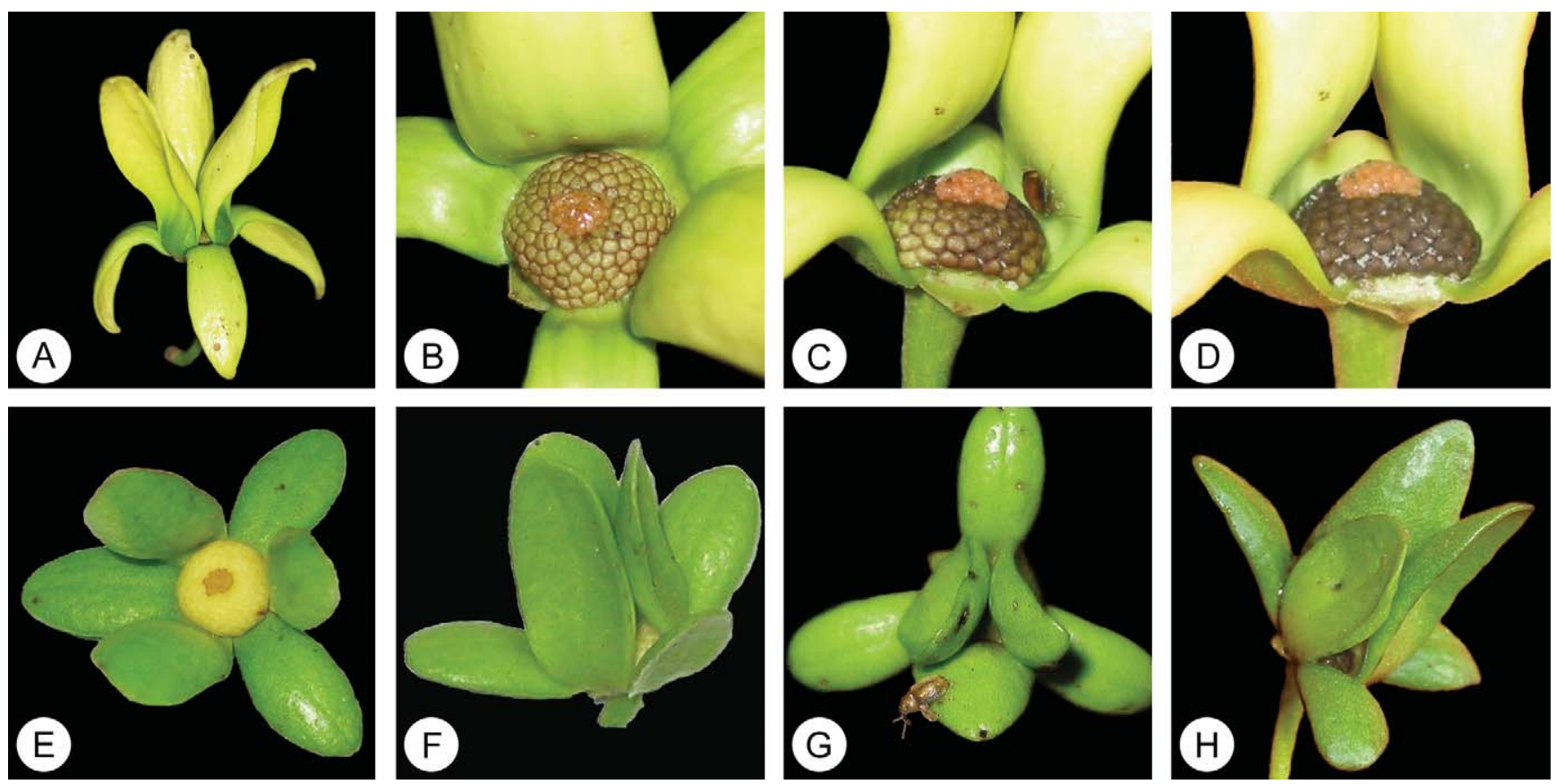

Fig. 3 Flower-level phenological changes in Polyalthia coffeoides and Polyalthia korinti during anthesis. A, Flower of $P$. coffeoides in stage VI (immediately before pistillate phase), with pollination chamber formed by three inner petals. B, Flower of $P$. coffeoides in pistillate phase (stage VII), with inner petals artificially separated to show glistening stigmatic cap (one inner petal removed). C, Flower of $P$. coffeoides in interim phase (stage VIII), with proximal inner petal removed, showing curculionid beetle. D, Flower of $P$. coffeoides in staminate phase (stage IX), with proximal inner petal removed, showing dark brown dehiscent stamens. E, Flower of $P$. korinti in stage IV, showing partially erect inner petals. $F$, Flower of $P$. korinti in stage VI (immediately before pistillate phase). G, Flower of $P$. korinti in pistillate phase (stage VII), showing curculionid beetle. H, Flower of P. korinti in staminate phase (stage IX). 

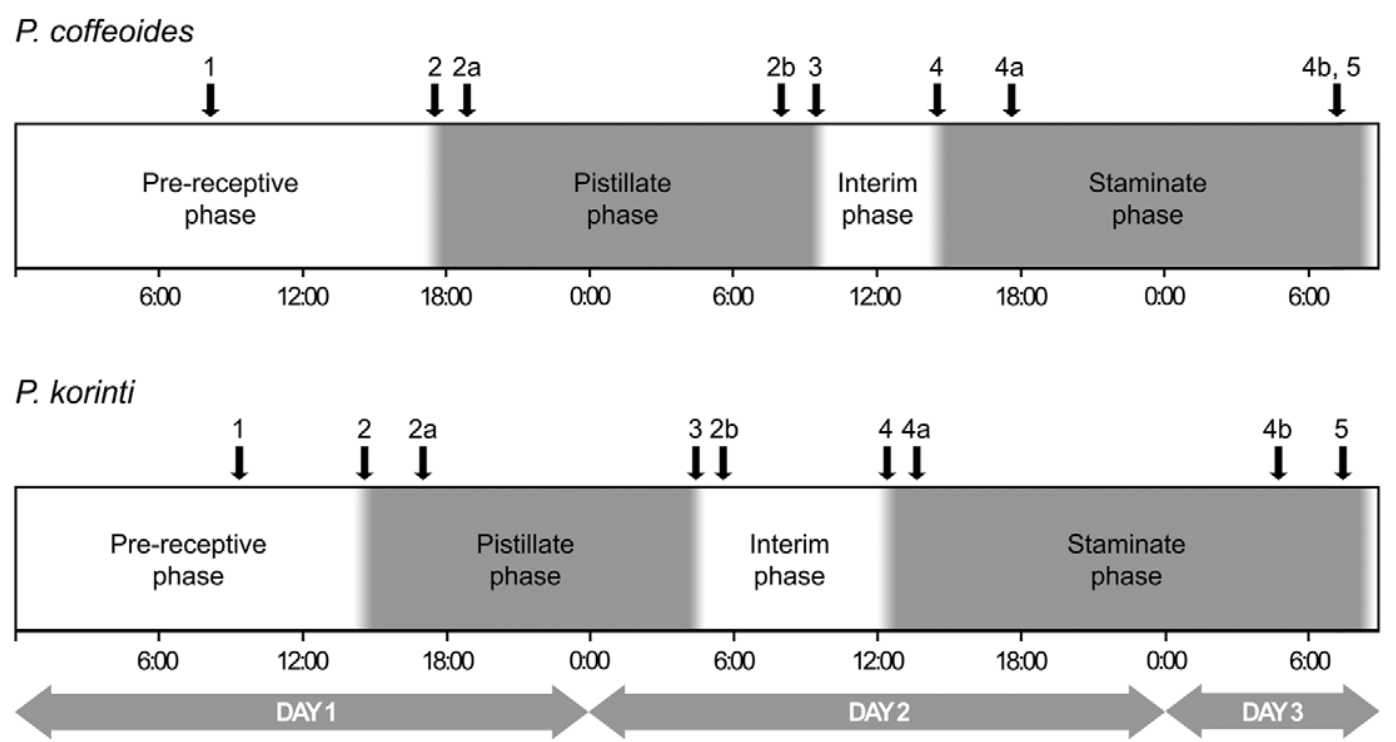

Fig. 4 Timing of phenological events during sexually functional phases of flowers of Polyalthia coffeoides (top) and Polyalthia korinti (bottom). Numerical codes: 1 , inner petals form pollination chamber over reproductive organs; 2 , stigmatic receptivity, thermogenesis, and scent production begin; $2 a$, arrival of pollinators; $2 b$, departure of pollinators; 3 , stigmatic receptivity and scent production end; 4 , anther dehiscence, thermogenesis, and scent production begin; $4 a$, arrival of pollinators; $4 b$, departure of pollinators; 5 , anther dehiscence and scent production end, and petals abscise.

Nitidulidae), and two unidentified cockroach species (Blattaria). The same Endaeus weevil species was observed in flowers of $P$. korinti, as was one unidentified cockroach species.

Endaeus weevils (fig. 6A, 6B) were the most common visitors to both Polyalthia species, with each floral chamber containing up to eight individuals (in P. coffeoides) or six individuals (in $P$. korinti) concurrently. The weevils most commonly landed on the apex of the inner petals or the adaxial surface of the outer petals (occasionally at the mouth of the apical aperture between the inner petals) before entering the floral chamber. The weevils were crepuscular and nocturnal, with their arrival at the flowers occurring between 1800 and 2200 hours ( $2 a$ in fig. 4). They remained overnight inside the floral chamber before departing at ca. 0500-0800 hours the following morning ( $2 b$ in fig. 4). A correlation exists between the number of individuals per floral chamber and the occurrence of the pistillate and staminate phases of the flower (fig. 7), with a notable absence of weevils during the interim phase of the flower. The weevils were generally present in pairs or larger groups and were often observed copulating, although neither eggs nor larvae were ever observed in older flowers. Brown spots on the petals suggest that the weevils feed on petals during their visit.

Carpophilus plagiatipennis (fig. 6C, 6D) was also observed inside the floral chamber of $P$. coffeoides, although it was considerably less common, with a maximum of two individuals present in the same flower at any one time. As with the Endaeus species, C. plagiatipennis is crepuscular and nocturnal, with similar time of arrival and departure from the flower (fig. 4).

Pollen grains of Polyalthia were observed on the bodies of both beetle species (fig. 8A), particularly on the dorsal surface and around the mouthparts. Hairs on the bodies of the beetles presumably assist with pollen attachment.
The flowers of both Polyalthia species were also closely associated with black ants belonging to the genus Technomyrmex (Hymenoptera: Formicidae subfam. Dolichoderinae), which built their nests using fragments of periderm, covering the entire flower before the onset of the pistillate phase. The ants remained until after petal abscission, although the petals sometimes failed to drop because the ants had connected the petals to each other and with the pedicel. Numerous pollen grains were found on the head and mouthparts of the ants (fig. $8 B$ ), clearly indicating that they consume pollen grains.

\section{Discussion}

\section{Floral Phenology and Morphology}

Protogyny is ubiquitous in the Annonaceae, as an adaptation to minimize the chance of within-flower pollination. In Polyalthia coffeoides and Polyalthia korinti, there is a 6-12-h interim period between the end of the pistillate phase and the onset of anther dehiscence, ensuring absolute avoidance of within-flower pollination. This is common in many Annonaceae, although there are also reports of limited overlap between the pistillate and staminate phases in some species (e.g., Polyalthia littoralis: Okada 1990).

Both the Polyalthia species reported here show a 2-d reproductive rhythm. This again is common in the Annonaceae (and is observed, e.g., in Enicosanthum cf. paradoxum; Silberbauer-Gottsberger et al. 2003), although species with unisexual flowers (e.g., Pseuduvaria; Silberbauer-Gottsberger et al. 2003) inevitably show a 1-d cycle. Longer reproductive rhythms occasionally occur, as in Asimina (Willson and Schemske 1980; Norman and Clayton 1986; Norman et al. 


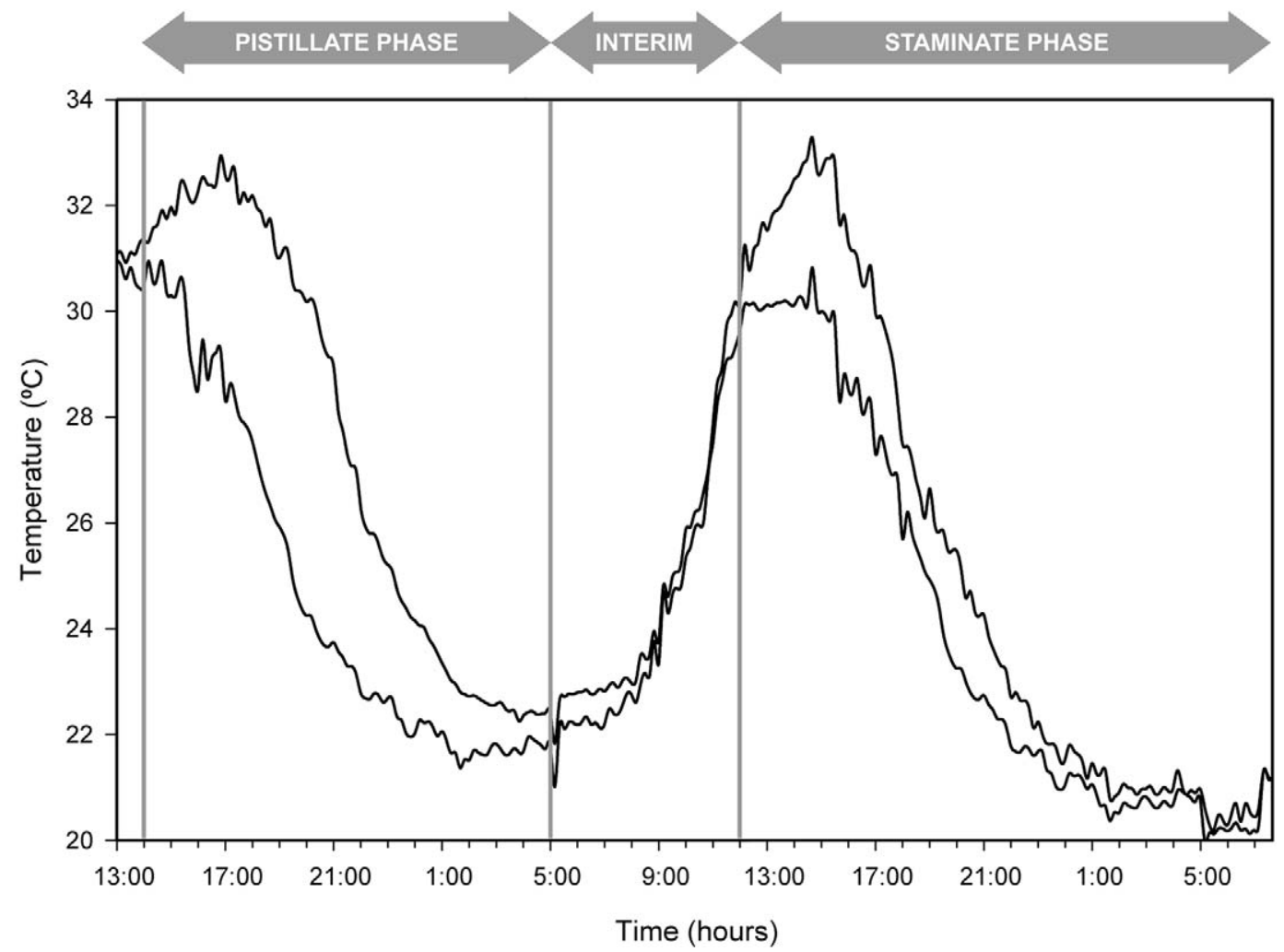

Fig. 5 Floral thermogenesis in Polyalthia korinti during pistillate, interim, and staminate phases. Bottom line $=$ ambient temperatures. Top line $=$ internal flower temperatures.

1992; Rogstad 1993), Deeringothamnus (Norman 2003), and Monodora (Lamoureux 1975).

The formation of a floral pollination chamber is widespread in the Annonaceae. In Polyalthia coffeoides and P. korinti, the chamber forms by the union of the convex adaxial surface of the three inner petals. Similar chambers are observed in genera such as Artabotrys and Xylopia, in which the bases of all six petals tightly surround the reproductive organs. In other genera, the pollination chamber is derived from imbricate petals (e.g., some Annona species), apically connivent inner petals

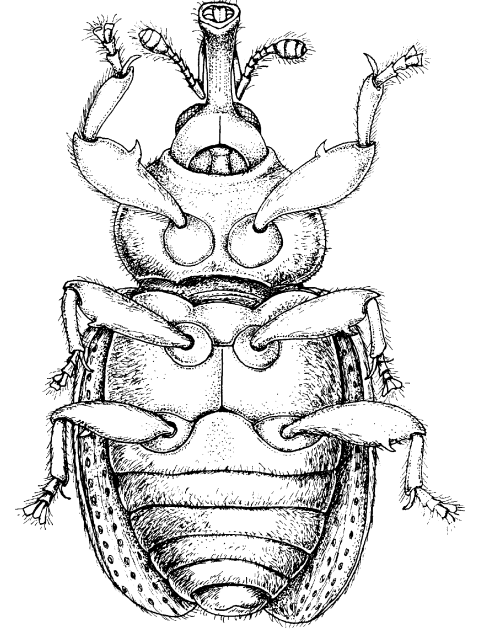

A
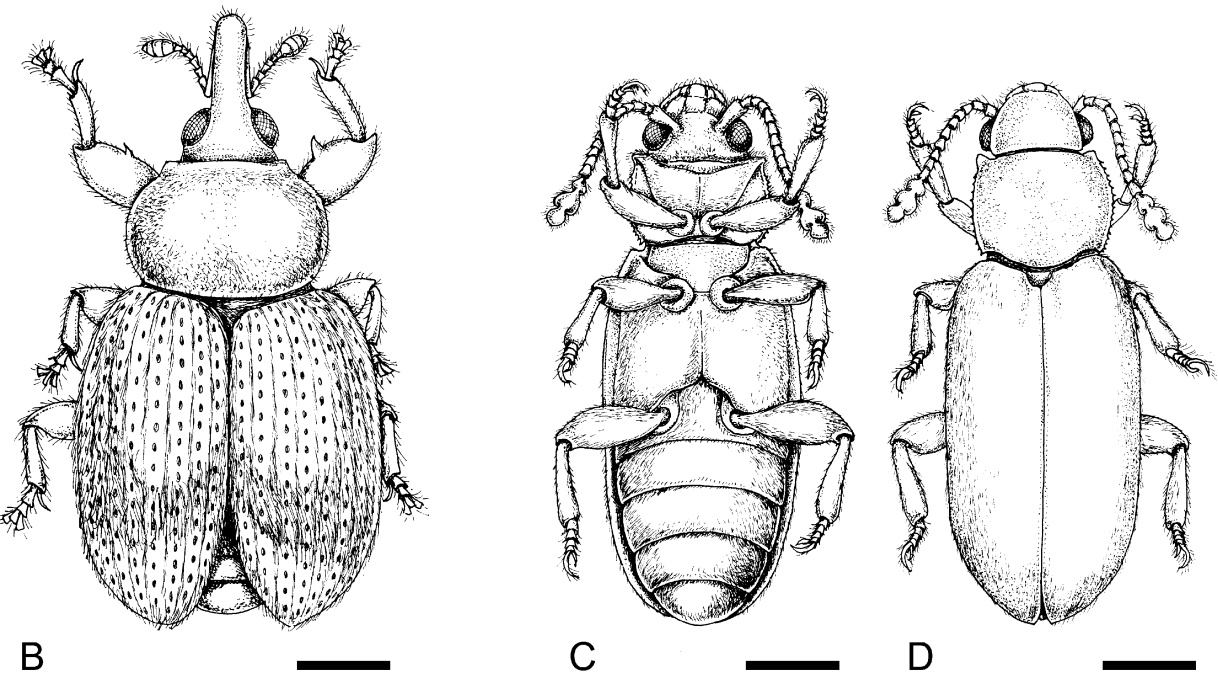

Fig. 6 Pollinators of Polyalthia coffeoides and Polyalthia korinti. A, B, Endaeus sp. (Curculionidae). C, D, Carpophilus plagiatipennis (Nitidulidae). Scale bars $=0.5 \mathrm{~mm}$. Drawings by Ngai Yuen Yi. 

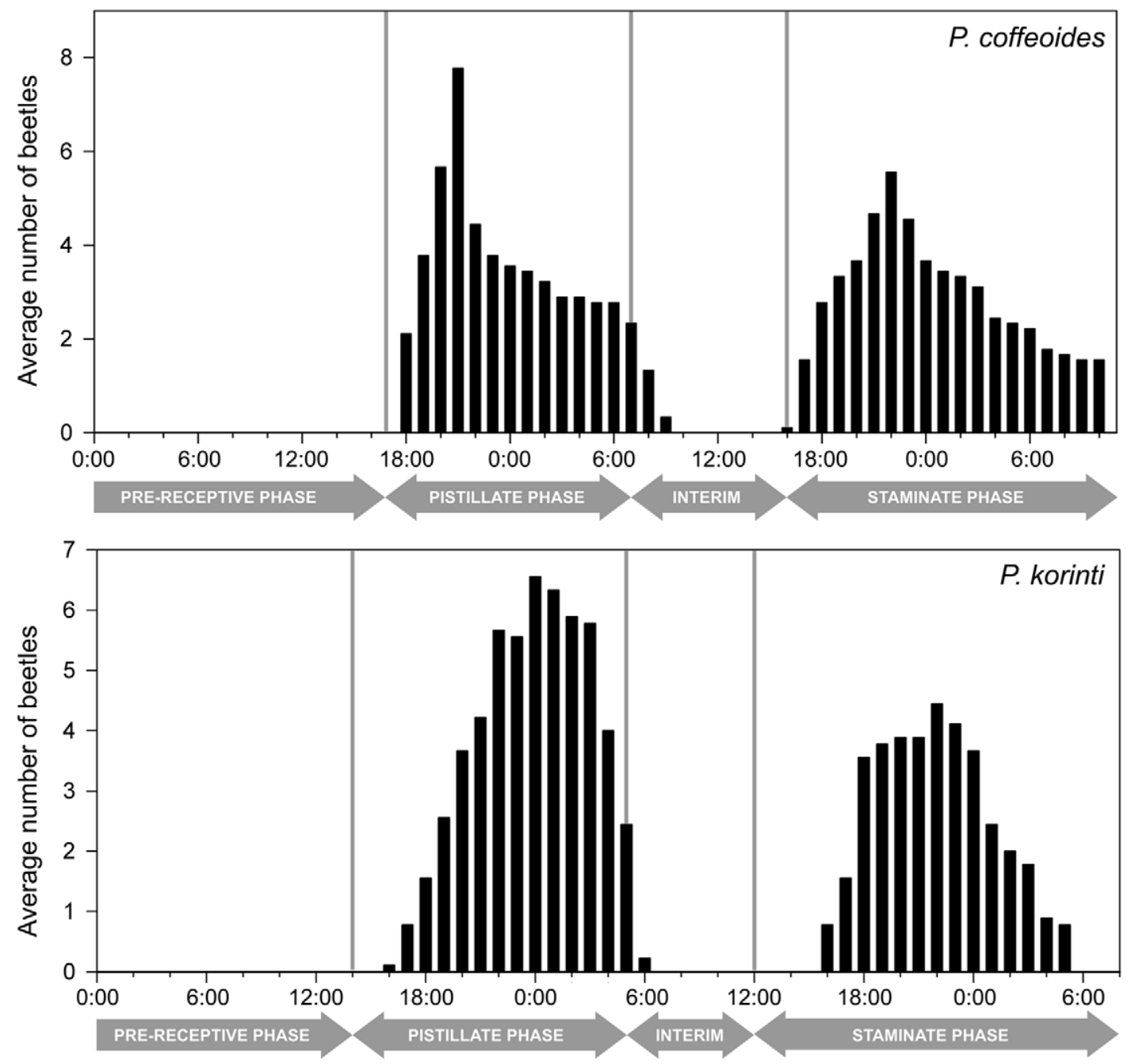

Fig. 7 Average number of Endaeus beetles per floral chamber in Polyalthia coffeoides and Polyalthia korinti during different phenological stages.

(e.g., Goniothalamus and Orophea), or apically connivent outer petals (e.g., Dasymaschalon). The diverse structural basis of these chambers is presumably a reflection of their independent evolutionary origin with the Annonaceae.

The sticky pollenkitt present in both species and the short pollen-connecting threads (PCTs) observed in P. coffeoides are likely to be adaptations enhancing the efficiency of pollen transfer to the beetle by creating large aggregates of pollen grains. Similar PCTs have been observed in diverse genera, including several in the Annonaceae, namely, Annona, Cardiopetalum, Cymbopetalum, Porcelia, and Pseuduvaria (Morawetz and Waha 1991; Su and Saunders 2003). The occurrence of PCTs is probably more widespread than currently recognized because most are not composed of sporopollenin and are therefore destroyed by acetolysis preparation techniques.

\section{Floral Thermogenesis}

The temperature data presented here indicate marked thermogenesis in $P$. korinti, with elevated internal temperatures of more than $6^{\circ} \mathrm{C}$ above ambient levels. Thermogenesis has been reported for several other genera in the family, including Anaxagorea (Küchmeister et al. 1998; Jürgens et al. 2000), Annona (Gottsberger 1970, 1989a, 1989b, 1999; Gottsberger and Silberbauer-Gottsberger 1988; Maas-van de Kamer 1993; Silberbauer-Gottsberger et al. 1997), Cymbopetalum (Murray 1993; Webber and Gottsberger 1993), Duguetia (Küchmeister et al. 1998; Silberbauer-Gottsberger et al. 2001, 2003), Enicosanthum (Silberbauer-Gottsberger et al. 2003), and Xylopia (R. M. C. S. Ratnayake, personal observation; Küchmeister et al. 1998; Silberbauer-Gottsberger et al. 2003), all of which are beetle-pollinated. It is likely that thermogenesis is more widespread in the Annonaceae than these data suggest, however, because it has not been investigated in most of the previous studies.

One possible role of floral thermogenesis is as a heat reward for floral visitors (Seymour et al. 2003). By providing beetles with this energy reward, the flower allows them to conserve considerable levels of energy required for feeding, mating, and initiating flight. The temperatures maintained by 

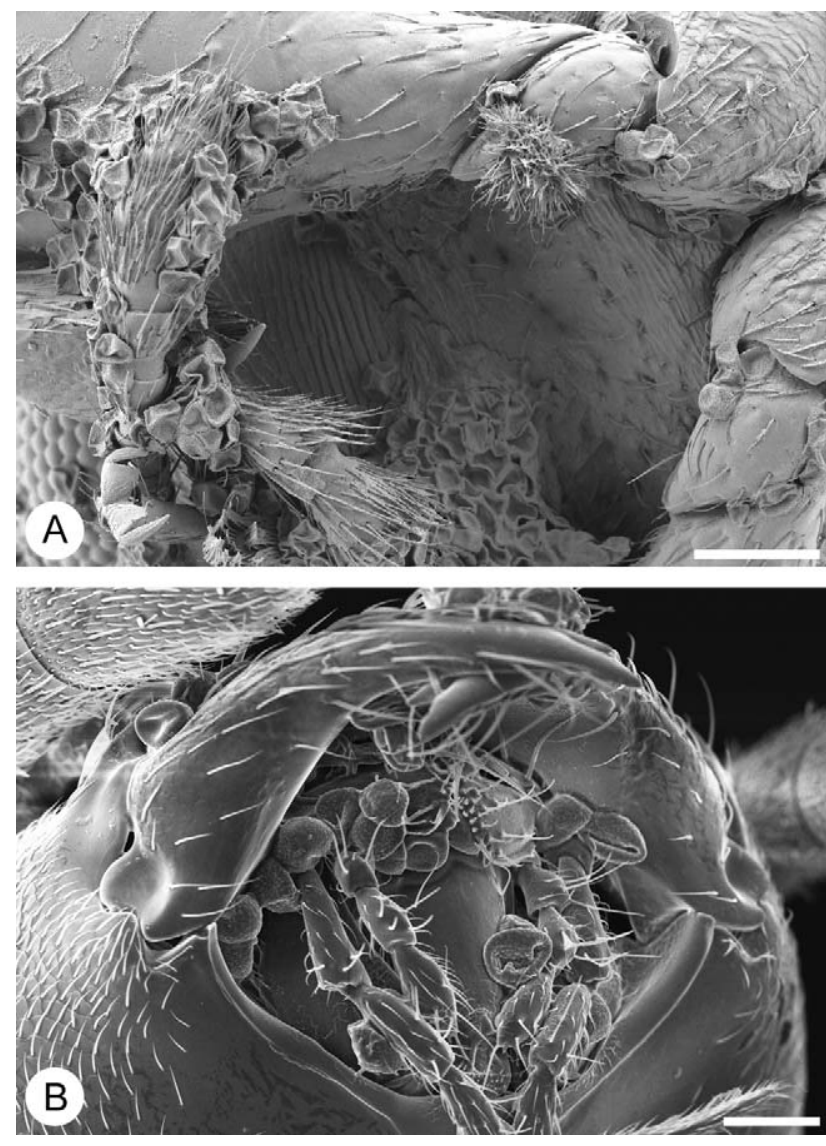

Fig. 8 Polyalthia pollen grains deposited on the bodies of Endaeus beetles $(A)$ and Technomyrmex ants $(B)$. Scale bars: $A=100 \mu \mathrm{m}$; $B=50 \mu \mathrm{m}$.

thermogenic flowers are typically in the range favored by active beetles (Seymour and Schultze-Motel 1997); the flowers therefore assist with the maintenance the body temperature of the beetles and stimulate their reproductive behavior, feeding, and digestion (Bernal and Ervik 1996; Patiño et al. 2000; Thien et al. 2000). Significantly, beetles require high thoracic temperatures (often above $30^{\circ} \mathrm{C}$ ) to initiate flight (Seymour and Schultze-Motel 1996, 1997; Seymour et al. 2003).

Recent research has found that some beetles (including some Curculionidae; Hausmann et al. 2004) have infrared sensors known as IR sensilla or IR pit organs, which detect infrared radiation (Schmitz et al. 1997; Hammer et al. 2001; Sowards et al. 2001). Although there is no evidence that such sensors exist on the pollinators of $P$. coffeoides or P. korinti, it is possible that the heat is generated in the flower as a direct attractant rather than simply an energy reward.

\section{Floral Visitors and Pollinators}

The Endaeus species (Curculionidae) was the most frequent visitor to flowers of both $P$. coffeoides and P. korinti. It can be determined as the most effective pollinator on the basis of the following attributes: (1) species' arrival time coincides with the onset of the functionally active phases of the flowers, with an increase in frequency during the pistillate and staminate phases but a decrease in frequency during the interim phase; (2) the body size (ca. $4 \mathrm{~mm}$ long, ca. $2 \mathrm{~mm}$ wide) is sufficiently small to enable access through the apertures in the floral chamber; (3) pollen grains of Polyalthia were observed attached to the visitors' bodies; and (4) species members were observed actively flying between flowers. Carpophilus plagiatipennis (Nitidulidae) can similarly be determined as an effective pollinator of $P$. coffeoides, although it is likely to be less important because visits were less common.

Previous reports of Polyalthia species also suggest pollination by Curculionidae and Nitidulidae (Polyalthia cauliflora: Momose et al. 1998b; P. cf. cauliflora: Silberbauer-Gottsberger et al. 2003; Polyalthia rumphii: Momose et al. 1998b), while Nagamitsu and Inoue (1994) observed that Chrysomelidae beetles were the dominant pollinator of an unnamed Polyalthia species in Sarawak. Small unidentified beetles have been observed as floral visitors to Miliusa wightiana (Devy and Davidar 2003), which is possibly related to P. korinti. Similarly, medium-sized Scarabaeidae and Chrysomelidae beetles have been observed pollinating Enicosanthum coriaceum (Momose et al. 1998b) and Enicosanthum cf. paradoxum (SilberbauerGottsberger et al. 2003), and small Curculionidae beetles have been observed pollinating Enicosanthum macranthum (Momose et al. 1998b), which are all possible relatives of $P$. coffeoides. Pollination by small beetles (particularly in the families Chrysomelidae, Curculionidae, Nitidulidae, and Staphylinidae) is extremely common in the Annonaceae (Gottsberger 1999; Silberbauer-Gottsberger et al. 2003) and is likely to represent the ancestral pollination system in the family.

The unidentified cockroach species are unlikely to be effective pollinators because they were observed to be generally diurnal in activity (and hence not active during the receptive phases of the flower) and were not observed to actively move between flowers. Blattelidae cockroaches have been suggested as the pollinators of Uvaria elmeri in Borneo (Nagamitsu and Inoue 1997), although these were much larger, nocturnal cockroaches, and Uvaria flowers lack the pollination chamber observed in P. coffeoides and P. korinti.

The association with Technomyrmex ants (Formicidae subfam. Dolichoderinae) is also unlikely to result in pollination. Ants are social insects and are unlikely to be efficient pollinators of tropical trees because of their behavior (Jolivet 1996). Although they were observed to move between flowers on the same tree, there is no evidence that they move between different individuals.

\section{Conclusions}

The primary pollinator of both $P$. coffeoides and $P$. korinti is shown to be a species of Endaeus weevil (Curculionidae), although $P$. coffeoides is also pollinated by Carpophilus plagiatipennis (Nitidulidae). Although $P$. coffeoides and $P$. korinti show clear adaptations for small-beetle pollination, the beetles are fruit eaters and are not specialized as pollinators. Not only is the same Endaeus species shown to be the primary pollinator of both $P$. coffeoides and P. korinti, but Carpophilus plagiatipennis is known to be the primary pollinator of Goniothalamus gardneri (R. M. K. Saunders, personal observation).

The beetles are attracted to the flowers by an alcoholic to fermented fruitlike scent that mimics the natural foods of the 
beetles. A preliminary analysis of floral scent chemistry using solid phase microextraction and gas chromatography-mass spectrometry was also conducted (results not shown). The scents consisted of several polysubstituted benzenoid compounds; although some of these compounds are likely to be of anthropogenic origin, others (including toluenes and benzenoid hydrocarbons) possibly act as beetle attractants.

It is also possible that the beetles are attracted by infrared radiation (heat) generated within the flower, although it remains to be shown whether Endaeus and Carpophilus species possess this ability. The rewards provided by the flowers include heat energy (for the maintenance of body temperature) and food (petals and pollen), and the floral chamber may furthermore provide protection from predators. The predominantly green or greenish yellow petals in $P$. korinti and $P$. coffeoides, respectively (fig. 3), suggest that the beetles are not attracted to the flowers by visual cues. It is probable that the dull coloration of the flowers is an adaptation to minimize destruction through herbivory.

Considerable empirical data have been accumulated to suggest that pollination systems are often diversified and opportunistic (e.g., Waser et al. 1996) and that specialized pollination systems that focus on a specific group of pollinators are less common than previously thought. The information available on the pollination biology of the Annonaceae, including the new results presented here, suggest that distinct pollination systems are nonetheless apparent within this family.

The two Polyalthia species are largely sympatric in their distribution range within Sri Lanka (fig. 1). Polyalthia coffeoides is locally abundant in shaded valleys in dry and intermediate forests at low elevations up to $500 \mathrm{~m}$, whereas $P$. korinti occupies a more diverse range of habitats in dry, intermediate, and wet zones, up to an elevation of $750 \mathrm{~m}$ (Huber 1985). The two species co-occur and are codominant in Menikdena, and they are shown here to have overlapping flowering seasons and to share the same primary pollinator. It is probable that competition for pollinators between the two species will not be significant, however, because the beetles are highly abundant at the site and are therefore unlikely to be a limiting factor for the reproductive success of either Polyalthia species. Although the data presented here suggest that there are only one or two species of pollinators for these Polyalthia species, there is no evidence to suggest any specific one-to-one adaptation between the plant and beetle species; the same beetle has been observed as the primary pollinator of different species (sometimes in different genera), and it is possible that annual fluctuations in the population size of the beetles may affect which species is the dominant pollinator.

The flowers of both species are markedly protogynous, with a 6-12-h nonfunctional interim period between the pistillate and staminate phases. This clearly precludes intrafloral self-pollination, although interfloral self-pollination (between different flowers belonging to the same individual) is possible because of the apparent lack of synchrony in the sexual maturation of flowers. Rogstad (1994) examined the phenology of flower maturation in the Polyalthia hypoleuca species complex and discovered two patterns of intracohort dichogamy. In Polyalthia hypoleuca and Polyalthia sumatrana, two cohorts exist within populations, with floral maturation of one cohort delayed relative to the other so that the flowers of one cohort are pistillate when the other is staminate, thus ensuring xenogamy. In Polyalthia discolor, Polyalthia glauca, and Polyalthia multinervis, however, Rogstad (1994) showed that this pattern was supplemented by successive cohorts that include individuals with concurrent pistillate- and staminatephase flowers. It is unclear whether P. coffeoides and P. korinti show the latter pattern, or whether flower maturation is irregular.

The co-occurrence of pistillate- and staminate-phase flowers on single individuals suggests that self-pollination is possible despite the existence of complete intrafloral dichogamy. Significantly, the results of artificial controlled-pollination experiments and the analysis of patterns of genetic variation (Ratnayake et al. 2006) indicate that both P. coffeoides and P. korinti possess mixed-mating systems.

\section{Acknowledgments}

This research was funded by a grant to R. M. K. Saunders from the University of Hong Kong Committee on Research and Conference Grants. We are grateful to the Sri Lankan Archaeological Department for permission to conduct this research at Menikdena forest; Professor J. Edirisinghe and staff of the Natural History Museum, London, for the identification of floral visitors; Ngai Yuen Yi for the excellent illustrations; U. G. U. R. Bandara for assisting with the collection of field data; Dr. Y. C. F. Su for information on the phylogenetic position of the species studied; and Dr. Hiroshi Azuma, Dr. R. T. Corlett, Professor G. Gottsberger, Dr. L. Ramsden, Y. C. F. $\mathrm{Su}$, and two anonymous reviewers for helpful discussions.

\section{Literature Cited}

Bernal R, F Ervik 1996 Floral biology and pollination of the dioecious palm Phytelephas seemannii in Colombia: an adaptation to staphylinid beetles. Biotropica 28:682-696.

Carvalho R, AC Webber 2000 Biologia floral de Unonopsis guatterioides (A. D.C.) R.E. Fr., uma Annonaceae polinizada por Euglossini. Rev Bras Bot 23:421-425.

Dafni A 1992 Pollination ecology: a practical approach. Oxford University Press, Oxford.

Devy MS, P Davidar 2003 Pollination systems of trees in Kakachi, a mid-elevation wet evergreen forest in Western Ghats, India. Am J Bot 90:650-657.
Galen C, RC Plowright 1987 Testing the accuracy of using peroxidase activity to indicate stigma receptivity. Can J Bot 65:107-111.

Gottsberger G 1970 Beiträge zur Biologie von Annonaceen-Blüten. Oesterr Bot Z 118:237-279.

1985 Pollination and dispersal in the Annonaceae. Annonaceae Newsl 1:6-7.

1989a Beetle pollination and flowering rhythm of Annona spp. (Annonaceae) in Brazil. Plant Syst Evol 167:165-187.

$1989 b$ Comments on flower evolution and beetle pollination in the genera Annona and Rollinia (Annonaceae). Plant Syst Evol 167:189-194. 
1999 Pollination and evolution in Neotropical Annonaceae. Plant Spec Biol 14:143-152.

Gottsberger G, I Silberbauer-Gottsberger 1988 Pollination strategies of Annona species from the cerrado vegetation in Brazil. Lagascalia 15:665-672.

Hammer DX, H Schmitz, A Schmitz, HG Rylander, AJ Welch 2001 Sensitivity threshold and response characteristics ofinfrared detection in the beetle Melanophila acuminata (Coleoptera: Buprestidae). Comp Biochem Physiol A 128:805-819.

Hausmann C, J Samietz, S Dorn 2004 Visual orientation of overwintered Anthonomus pomorum (Coleoptera: Curculionidae). Environ Entomol 33:1410-1415.

Huber H 1985 Annonaceae. Pages 1-75 in MD Dassanayake, FR Fosberg, eds. A revised handbook to the flora of Ceylon. Vol 5. Amerind, New Delhi.

Jolivet P 1996 Ants and plants: an example of coevolution. 2nd ed. Backhuys, Leiden.

Jürgens A, AC Webber, G Gottsberger 2000 Floral scent compounds of Amazonian Annonaceae species pollinated by small beetles and thrips. Phytochemistry 55:551-558.

Kornerup A, JH Wanscher 1978 Methuen handbook of colour. Methuen, London.

Küchmeister H, AC Webber, I Silberbauer-Gottsberger, G Gottsberger 1998 A polinização e sua relação com a termogênese em espécies de Arecaceae e Annonaceae da Amazônia central. Acta Amazonica 28:217-245.

Lamoureux CH 1975 Phenology and floral biology of Monodora myristica (Annonaceae) in Bogor, Indonesia. Ann Bogor 6:1-25.

Maas-van de Kamer H 1993 Floral biology of Anaxagorea dolichocarpa, and some notes on flower biology in other Annonaceae. Annonaceae Newsl 9:19-24.

Mols JB, B Gravendeel, LW Chatrou, MD Pirie, PC Bygrave, MW Chase, PJA Keßler 2004 Identifying clades in Asian Annonaceae: monophyletic genera in the polyphyletic Miliuseae. Am J Bot 91:590-600.

Momose K, T Nagamitsu, T Inoue 1998a Thrips cross-pollination of Popowia pisocarpa (Annonaceae) in a lowland dipterocarp forest in Sarawak. Biotropica 30:444-448.

Momose K, T Yumoto, T Nagamitsu, M Kato, H Nagamasu, S Sakai, RD Harrison, T Itioka, AA Hamid, T Inoue 1998b Pollination biology in a lowland dipterocarp forest in Sarawak, Malaysia. I. Characteristics of the plant-pollinator community in a lowland dipterocarp forest. Am J Bot 85:1477-1501.

Morawetz W, M Waha 1991 Zur Entstehung und Funktion pollenverbindender Fäden bei Porcelia (Annonaceae). Beitr Biol Pflanz 66: 145-154.

Murray NA 1993 Revision of Cymbopetalum and Porcelia (Annonaceae). Syst Bot Monogr 40:1-121.

Nagamitsu T, T Inoue 1994 Flower-visiting insects collected in lowland dipterocarp forests in Lambir Hills National Park, Sarawak. Pages 142-150 in T Inoue, AA Hamid, eds. Plant reproductive systems and animal seasonal dynamics: long-term study of dipterocarp forest in Sarawak. Centre for Ecological Research, Kyoto University, Otsu, Japan.

- 1997 Cockroach pollination and breeding system of Uvaria elmeri (Annonaceae) in a lowland mixed-dipterocarp forest in Sarawak. Am J Bot 84:208-213.

Norman EM 2003 Reproductive biology of Deeringothamnus rugelii and D. pulchellus (Annonaceae). Taxon 52:547-555.

Norman EM, D Clayton 1986 Reproductive biology of two Florida pawpaws: Asimina obovata and A. pygmaea (Annonaceae). Bull Torrey Bot Club 113:16-22.

Norman EM, K Rice, S Cochran 1992 Reproductive biology of Asimina parviflora (Annonaceae). Bull Torrey Bot Club 119:1-5.

Okada H 1990 Reproductive biology of Polyalthia littoralis (Annonaceae). Plant Syst Evol 170:237-245.
Olesen JM 1992 Flower mining by moth larvae vs. pollination by beetles and bees in the cauliflorous Sapranthus palanga (Annonaceae) in Costa Rica. Flora 187:9-15.

Patiño S, J Grace, H Bänzinger 2000 Endothermy by flowers of Rhizanthes lowii (Rafflesiaceae). Oecologia 124:149-155.

Ratnayake RMCS, YCF Su, IAUN Gunatilleke, DSA Wijesundara, RMK Saunders 2006 Reproductive biology of two sympatric species of Polyalthia (Annonaceae) in Sri Lanka. II. Breeding systems and population genetic structure. Int J Plant Sci 167:495-502.

Rogstad SH 1993 Variability in timing of sexual phases in the North American pawpaw, Asimina triloba (L.) Dunal (Annonaceae). Trillium 2:5-8.

1994 The biosystematics and evolution of the Polyalthia bypoleuca species complex (Annonaceae) of Malesia. III. Floral ontogeny and breeding systems. Am J Bot 81:145-154.

Schmitz H, H Bleckmann, M Murtz 1997 Infrared detection in a beetle. Nature 386:773-774.

Seymour RS, P Schultze-Motel 1996 Thermoregulating lotus flowers. Nature 383:305.

- 1997 Heat-producing flowers. Endeavour 21:125-129.

Seymour RS, CR White, M Gibernau 2003 Heat reward for insect pollinators. Nature 426:243-244.

Silberbauer-Gottsberger I, G Gottsberger, AC Webber 2003 Morphological and functional flower characteristics of New and Old World Annonaceae with respect to their mode of pollination. Taxon 52: 701-718.

Silberbauer-Gottsberger I, RA Gottsberger, G Gottsberger 1997 Rhythm of flowering and pollination of a hybrid population of Annona in a small cerrado area in Mato Grosso, Brazil. Annonaceae Newsl 11:55-60.

Silberbauer-Gottsberger I, AC Webber, H Küchmeister, G Gottsberger 2001 Convergence in beetle-pollinated central Amazonia Annonaceae, Araceae, Arecaceae, and Cyclanthaceae. Pages 165-183 in G Gottsberger, S Liede, eds. Life forms and dynamics in tropical forests. J. Cramer, Berlin.

Somaweera R, K Ukuwela, S Karunaratne 2001 Menikdena: a local herpetofauna hotspot. Occas Pap Amphib Reptile Res Organ Sri Lanka 2:1-8.

Sowards LA, H Schmitz, DW Tomlin, RR Naik, MO Stone 2001 Characterization of beetle Melanophila acuminata (Coleoptera: Buprestidae) infrared pit organs by high-performance liquid chromatography/mass spectrometry, scanning electron microscope, and Fourier transform-infrared spectroscopy. Ann Entomol Soc Am 94: 686-694.

Su YCF, JB Mols, W Takeuchi, PJA Keßler, RMK Saunders 2005 Reassessing the generic status of Petalolophus (Annonaceae): evidence for the evolution of a distinct sapromyophilous lineage within Pseuduvaria. Syst Bot 30:494-502.

Su YCF, RMK Saunders 2003 Pollen structure, tetrad cohesion, and pollen-connecting threads in Pseuduvaria (Annonaceae). Bot J Linn Soc 143:69-78.

Thien LB, H Azuma, S Kawano 2000 New perspectives on the pollination biology of basal angiosperms. Int J Plant Sci 161(suppl): S225-S235.

Waser NM, L Chittka, MV Price, NM Williams, J Ollerton 1996 Generalization in pollination systems, and why it matters. Ecology 77:1043-1060.

Webber AC, G Gottsberger 1993 Floral biology and pollination of Cymbopetalum euneurum in Manaus, Amazonia. Annonaceae Newsl 9:25-28.

1995 Floral biology and pollination of Bocageopsis multiflora and Oxandra euneura in central Amazonia, with remarks on the evolution of stamens in Annonaceae. Feddes Repert 106:515-524.

Willson MF, DW Schemske 1980 Pollinator limitation, fruit production, and floral display in pawpaw (Asimina triloba). Bull Torrey Bot Club 107:401-408. 